\title{
Preface Of INda
}

When starting the first issue;

"Journal of Interior Design and Academy" (INda), which started its publication life on May 19, 2021, within the scope of Octagon Academy, is experiencing excitement and happiness together thanks to publishing its first issue.

Scientific resources, researches and studies have accelerated and started to spread with technology. The place and importance of scientific journals in the presentation and spread of studies, especially in academic working life, is very big. Today, it is possible to reach most of the scientific articles in the world through scientific journals published online. It is estimated that there are approximately 24 thousand scientific journals in the world and between 2.2-2.5 million scientific articles are produced. Unfortunately, this rate is very low in Turkey and the number of indexed journals based on the faculty of architecture and design is very low. In the field of interior architecture, the number of indexed journals specific to the discipline of interior architecture is not sufficient. The Journal of Interior Design and Academy (INda) has decided to start its publication life for exactly these reasons. The journal that has just started its publication life; has emerged with the aim of making versatile contributions to our country, universities, interior architecture field and related disciplines and professionals working in this field in terms of production and sharing of scientific knowledge in the context of its goals, duties and responsibilities.

\section{Moreover;}

- To encourage the production of research and scientific articles towards interior architecture and related disciplines,

- To contribute to increasing the number of scientific and peer-reviewed journals on interior architecture and related disciplines,

- To encourage the production of scientific articles from graduate thesis studies, 
- To make it an internationally acceptable, readable, scannable, qualified and scientific journal within the scope of Interior Architecture,

- To provide the stakeholders with benefit from the published articles,

- To create and disseminate a common platform in such a way as to ensure joint working awareness and awareness of interior architecture and related theoretical and practical disciplines of architecture, spatial planning, design, conservation, restoration and management.

The discipline of interior architecture can continue to work in relation to different disciplines such as architecture, industrial product design, planning, landscape architecture. The coming together and working together of these disciplines on different platforms supports holistic design approach. For the coexistence of these disciplines, there is a need for a common language and more collaborative work. In this context, it has emerged that the publication of this journal is a basic need in order to create a scientific platform for the understanding of Interior Architecture and related disciplines, sharing information and collaborating.

I hope that with the first issue of our journal, which started its publication life in Turkish and English with two issues a year, it will be useful to the interior architecture and design disciplines in the future in terms of achieving goals that can be recognized on an international scale, producing information and providing information sharing widely. 